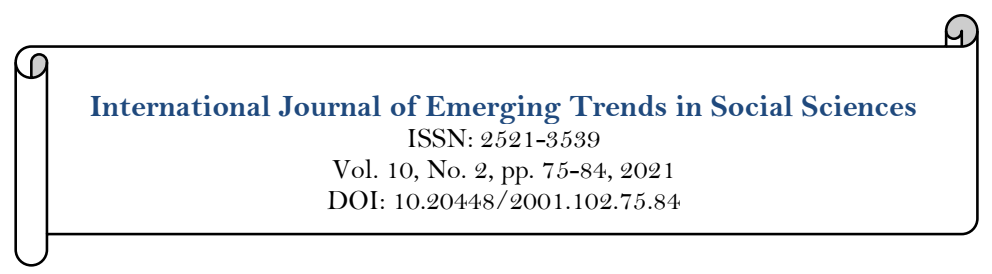

\title{
Model of Mitigation: Strategies to Utilise Unique Insider Research Opportunities
}

\author{
Nerolie Dever ${ }^{1}$ \\ Lisa Barnes ${ }^{2 *}$ \\ Warrick Long ${ }^{3}$ \\ 1,2,s Avondale University, NSW, Australia. \\ sEmail:lisa.barnes@avondale.edu.au
}

\begin{tabular}{|c|c|}
\hline Abstract & \\
\hline $\begin{array}{l}\text { Insider research has in the past challenged researchers in terms of blurred } \\
\text { lines, objectivity, bias confidentiality and maintaining professional working } \\
\text { relationships. The opportunities it presents however include access to } \\
\text { information, trust in the data collection, insider and intimate knowledge, } \\
\text { and the ability for rich inside data collection. This paper discusses these } \\
\text { opportunities and challenges, then makes recommendations for ten strategies } \\
\text { to assist in data collection by an insider researcher. These strategies include } \\
\text { communication, mixed methods, reflections, debrief, distance, confidentiality, } \\
\text { interview technique, social network, voluntary and objectivity. The research } \\
\text { concludes with the creation of a Model of Mitigation, which posits the ten } \\
\text { mitigation strategies along with the four opportunities to assist insider } \\
\text { researchers to overcome obstacles when conducting insider research, as } \\
\text { insider research has been shown to collect rich data and enable organisations } \\
\text { to reflect on the research findings and to implement recommendations made } \\
\text { on an individual but organisation wide basis. }\end{array}$ & $\begin{array}{l}\text { Keywords: } \\
\text { Insider research } \\
\text { Model of mitigation } \\
\text { Insider-Outsider continuum. } \\
\text { Licensed: } \\
\text { This work is licensed under a } \\
\text { Creative Commons Attribution } 4.0 \\
\text { License. } \\
\text { Publisher: } \\
\text { Scientific Publishing Institute } \\
\text { Received: } 18 \text { May } 2021 \\
\text { Revised: } 23 \text { June } 2021 \\
\text { Accepted: } 28 \text { July } 2021 \\
\text { Published: } 26 \text { August } 2021 \\
\text { ( Corresponding Author) }\end{array}$ \\
\hline
\end{tabular}

Funding: This study received no specific financial support.

Competing Interests: The authors declare that they have no competing interests.

\section{Introduction}

This paper explores the benefits and challenges associated with investigating the workplace where a researcher is employed, (known as insider research), as well as detailing some mitigation strategies. Costley, Elliott, and Gibbs (2010) state that "work based research can provide this evidence to influence policy and decision making, and can also make a difference to individual practice." In addition, they reference Nixon who outlines that "people who undertake insider-led research can make significant change".

\section{Insider Research Defined}

Insider research is "conducted within a social group, organization or culture of which the researcher is also a member" (Greene, 2014). Trowler (2011) calls this research 'endogenous research'. The person conducting the research is a full member of the "organisation and not one who joins the organisation temporarily for the purpose of the research" (Kenneally, 2013). They are members of the organisation (Brannick \& Coghlan, 2007), or research field before the research project commences (Moore, 2012). Breen (2007) indicates that insider researchers are typically "intimately engaged" with their field of research. The opposite of an inside researcher is an outsider researcher who does not belong to the group being studied (Breen, 2007; Moore, 2012) 
Saidin and Yaacob (2016) discuss the two schools of thought in relation to insiders and outsiders. The first is that an insider cannot be objective, so the outsider researcher, because they are detached, are best placed to be impartial. The opposing view is that the outside researcher cannot fully understand a topic that they are working on due to being separate from the area of research, or field of research and as a result, they will not be able to legitimise the research findings.

"There has been a strong tradition of professing a dichotomy between insider and outsider research" (Kirpitchenko \& Voloder, 2014). However, some authors argue that the polarity of insider-outsider is incorrect (Chavez, 2008; Merton, 1972). Numerous authors (Breen, 2007; Greene, 2014; Mercer, 2007; Trowler, 2011) instead contend that the role of the researcher is conceptualized on a continuum; insider and outsider research are not opposing views. As a result of these thoughts, insiderness can be identified as not having a fixed value. Merton (1972) suggests that a researcher can find themselves an insider at one instant and an outsider at another.

It cannot be said that an insider or outsider researcher is more advantaged or better than the other. Merton (1972) has suggested that neither 'insiders' nor 'outsiders' have privileged access to information in the field, but rather the "different positions produce distinct knowledge, and that neither can be said to occupy a higher status in terms of 'objectivity,' 'subjectivity' or 'authenticity” (Kirpitchenko \& Voloder, 2014). Chavez (2008) in talking about insiders and outsiders, quotes Naples as stating that neither of them has "a monopoly on advantage or objectivity" and "what is lost on the swings is more than compensated for on the roundabouts"(Mercer, 2007).

Taylor (2011) takes the concept of being an insider further and uses the term 'intimate insider' to describe a researcher works at the deepest level within the organisation that they are a part of. Researchers may have pre-existing friendships in the field and these "evolve into informant relationships-friend informants- as opposed to the majority of existing work that deals with informant-friendships." Being a researcher and facing the many challenges that are associated with research work, is not dependant on being identified as an insider or an outsider (Saidin \& Yaacob, 2016). Certainly, insider researchers may have to deal with issues such as research methods and ethical concerns that could be classed as irrelevant to outsider researchers (Breen, 2007; Greene, 2014).

Griffith (1998) in Kirpitchenko and Voloder (2014) states that "The who of research - the social relations of the researcher's biography - shapes the topic of research, the methodology used and the knowledge gained." Kirpitchenko \& Voloder continue this thought further by indicating that the researcher's identity, knowledge, experience and assumptions is very important as it has an influence on various aspects of the research being undertaken.

Taylor (2011) describes it when she says that "the field' is not only my site of work and learning, but it is my place of personal belonging, comfort, trust, friendship and love." Though the degree of 'insiderness' that is experienced does vary according to the site and more importantly staff they are interacting with. Researchers who will be completing the research, move along the insider-outsider continuum, (Breen, 2007; Greene, 2014; Trowler, 2011) though more time will be spent on the insider end.

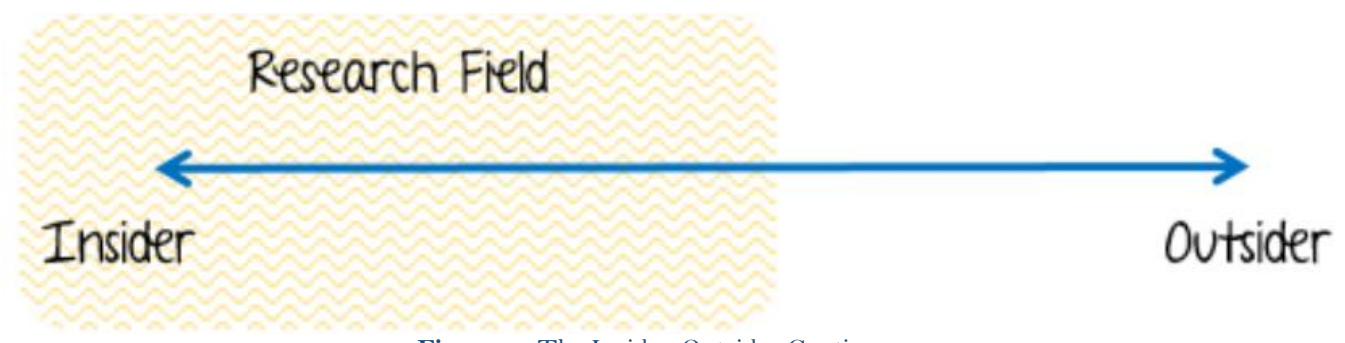

Figure-1. The Insider-Outsider Continuum.

\section{A Review of the Literature on Insider Research}

A variety of literature including on-line journals, journal articles, books, websites and conference proceeding were reviewed to identify what authors had identified as the benefits and challenges associated with investigating the workplace where a researcher is employed as well as detailing some tools and techniques to assist when conducting insider research. While there was literature available that discussed insider research, it was found that the vast majority of this literature as detailed in Table 1 insider research article information, related to insider research within the service sector, primarily education. No literature was identified that discussed insider research within the manufacturing industry. Many of the papers reviewed detailed the use of action research and qualitative research as the methodology.

The literature reviewed was sourced from publications dated 1972 through to 2019, with over sixty per cent of these published in the last 12 years. Table 2 shows the Year of Publication of Reviewed Literature. 
Table-1. Insider Research Article Information.

\begin{tabular}{|c|c|c|c|c|c|c|c|c|c|c|c|c|c|c|}
\hline Study Arena & $\begin{array}{l}\text { Total No. } \\
\text { of }\end{array}$ & \multicolumn{13}{|c|}{ Article No. } \\
\hline Education & 13 & 122 & 131 & 132 & 134 & 135 & 142 & 144 & 145 & 150 & 156 & 159 & 167 & 170 \\
\hline Medical & 5 & 136 & 140 & 160 & 162 & 165 & & & & & & & & \\
\hline Social & 8 & 139 & 141 & 143 & 149 & 153 & 161 & 164 & 168 & & & & & \\
\hline Corporate Business & 2 & 138 & 157 & & & & & & & & & & & \\
\hline Government & 1 & 151 & & & & & & & & & & & & \\
\hline Other Industry & 4 & 137 & 154 & 155 & 158 & & & & & & & & & \\
\hline $\begin{array}{c}\text { Non-Industry Specific (General } \\
\text { Info) }\end{array}$ & 9 & 133 & 146 & 147 & 148 & 152 & 163 & 166 & 169 & 171 & & & & \\
\hline Total & 42 & & & & & & & & & & & & & \\
\hline
\end{tabular}

Table-2. Year of Publication of Reviewed Literature.

\begin{tabular}{|c|c|c|c|c|c|c|c|c|}
\hline \multirow{2}{*}{$\begin{array}{l}\text { Year } \\
1972\end{array}$} & \multirow{2}{*}{$\begin{array}{c}\text { Total No. } \\
\text { of Articles }\end{array}$} & \multicolumn{7}{|c|}{ Article Number } \\
\hline & & 147 & & & & & & \\
\hline 1981 & 1 & 170 & & & & & & \\
\hline 1989 & 1 & 144 & & & & & & \\
\hline 1990 & $\mathrm{O}$ & & & & & & & \\
\hline 1998 & $\mathrm{O}$ & & & & & & & \\
\hline 1999 & 1 & 155 & & & & & & \\
\hline 2000 & 1 & 164 & & & & & & \\
\hline 2001 & 2 & 137 & 159 & & & & & \\
\hline 2002 & 2 & 141 & 157 & & & & & \\
\hline 2003 & $\mathrm{O}$ & & & & & & & \\
\hline 2004 & 2 & 156 & 168 & & & & & \\
\hline 2005 & 1 & 165 & & & & & & \\
\hline 2006 & $\mathrm{O}$ & & & & & & & \\
\hline 2007 & 7 & 139 & 142 & 152 & 153 & 154 & 166 & 169 \\
\hline 2008 & 2 & 136 & 143 & & & & & \\
\hline 2009 & 2 & 161 & 162 & & & & & \\
\hline 2010 & 2 & 132 & 148 & & & & & \\
\hline 2011 & 2 & 131 & 149 & & & & & \\
\hline 2012 & 5 & 122 & 140 & 145 & 158 & 163 & & \\
\hline 2013 & 2 & 151 & 167 & & & & & \\
\hline 2014 & 3 & 133 & 135 & 160 & & & & \\
\hline 2015 & $\mathrm{O}$ & & & & & & & \\
\hline 2016 & 2 & 134 & 146 & & & & & \\
\hline 2017 & 1 & 150 & & & & & & \\
\hline 2018 & 1 & 138 & & & & & & \\
\hline 2019 & 1 & 171 & & & & & & \\
\hline Total & 42 & & & & & & & \\
\hline
\end{tabular}

\section{Advantages of Insider Research}

Conducting insider research can have a number of advantages for the researcher during the research project as well as for the project outcome. Numerous authors (Brannick \& Coghlan, 2007; Chavez, 2008; Costley et al., 2010; Dwyer \& Buckle, 2009; Herrmann, 1989; Kirpitchenko \& Voloder, 2014; Mercer, 2007; 
Mitchell, 2008; Pitman, 2002; Saidin \& Yaacob, 2016) discussed the benefit of the researcher having ready access to people and information by researching in a familiar field. Not only does this save time but it means that the researcher can easily identify the key people that should be involved in the research. Mercer (2007) found that being an insider resulted in him having reduced travel time when researching and because he knew the field, he was afforded greater flexibility with regard to interview times. As an insider, Herrmann (1989) believed that much of the assistance that he received as an insider, he would not have received if he was an outsider. Mitchell (2008) stated that he felt that as an insider "the area where I was most at an advantage was with informants." Management permission to interview staff was readily given and documented information was also provided easily. The ease of access to people is also linked to the relationship between the researcher and the research participants. Being an insider, the researcher has a knowledge of the local language, social norms, culture and ways of working which will assist the researcher with understanding the issue under investigation (Herrmann, 1989; Kirpitchenko \& Voloder, 2014; Saidin \& Yaacob, 2016). "Consequently there is the possibility for stronger rapport and trusting relationships to be established" (Kirpitchenko \& Voloder, 2014). Related to having ready access to personnel and information, is that an insider already has the trust of the organisation (Dwyer \& Buckle, 2009) which may not be achieved by being an outsider. Mitchell (2008) identified that "Trust opened many doors for me as an insider." He found that management and staff were very interested in the research he was completing and he received a high level of personal trust in what he was doing that this eased and simplified his research. Being an insider can mean that there is little need to build rapport with the participants (Chavez, 2008; McDermid, Peters, Jackson, \& Daly, 2014; Mercer, 2007) as the participants trust the researcher. As a result, participants may be more frank with the researcher than would otherwise be the case (Dwyer \& Buckle, 2009; Mercer, 2007; Rooney, 2005). "sharing a similar identity allowed me to build an alliance with the students whom I was working” (Pitman, 2002). As an insider, the researcher has detailed knowledge about the field and the topic (Costley et al., 2010; Saidin \& Yaacob, 2016) and this is one of "the reasons that insider projects can be so fully informed and, arguably, better placed to propose effective change strategies" (Costley et al., 2010). The researcher does not have to concern themselves with learning about the topic under research or the research environment (Greene, 2014; Saidin \& Yaacob, 2016) which will provide an advantage to the researcher Mitchell (2008). The researcher's perspective is an informed one (Costley et al., 2010). Having a deeper knowledge and understanding about the field (Floyd \& Arthur, 2012) and the research topic will also mean that the researcher will address the practical issues associated with the topic which may not occur if an outsider completes the research (Herrmann, 1989). An outsider may focus on areas within the study which are irrelevant due to a lack of real knowledge about the topic. In addition to knowledge about the research topic, the insider also has knowledge about the language, values and customs in the research field (Brannick \& Coghlan, 2007; Herrmann, 1989; Herrmann, 1989; Holian, 1999). The insider has a knowledge of the people and the associated internal political structures which enables them to "operate within the system" (Herrmann, 1989).

Building on the benefits of insider knowledge, an insider has the benefit that data collection is easier as they know the field and work colleagues are "usually happy to talk, often welcoming the opportunity to discuss issues with someone who understands" (Greene, 2014), and they feel that they are "freer to talk openly and honestly" (Rooney, 2005). Taylor (2011) compared her data collected from 'friend-informants' and 'informantfriends' and identified that the information from 'friend-informants' was "significantly greater in volume and depth." By having a closer relationship with the participants Jodie found that she was more perceptive to their body language and non-verbals which aided in data collection. These advantages can be combined into Figure 2 showing them to be trust, knowledge, access and data collection.

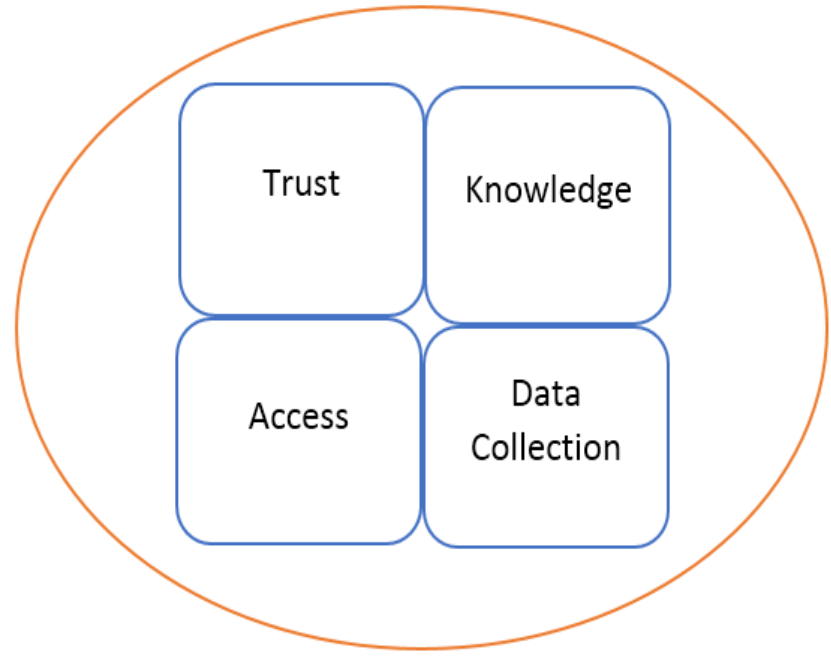

Figure-2. Insider Research Advantages. 


\section{Challenges Associated with Insider Research}

Kanuha (2000) wrote that "for each of the ways that being an insider researcher enhances the depth and breadth of understanding to a population that may not be accessible to a nonnative scientist, questions about objectivity, reflexivity, and authenticity of a research project are raised". Various authors, including those who have completed insider research, do identify a number of challenges for the insider researcher and these are outlined below.

A significant concern that numerous authors raised regarding insider research is the blurred line between the researchers work life and their research field (Brannick \& Coghlan, 2007; Breen, 2007; Chavez, 2008; DeLyser, 2001; Greene, 2014; Hepsø, 2012; Holian, 1999; Holian \& Brooks, 2004; Holian \& Coghlan, 2013; Kenneally, 2013; Kirpitchenko \& Voloder, 2014; Trowler, 2011). The insider is always in the field and has to manage having to be both a researcher and an employee; there is no distance from the research field for the researcher. There will be times when it may not be clear when research is being conducted and when it is not.

Adam (2013) during her research found that she "experienced multiple roles: Friend, colleagues or advisor, as well as being the researcher." She identified that this role ambiguity created challenges when collecting data. Floyd and Arthur (2012) identify that there can be tension for the insider as they struggle with the clarity between their role as a practitioner and as a researcher. "A practitioner is actively engaged in an organisation whereas a researcher needs to stand back and survey the evidence." This can result in 'role conflict" (Brannick \& Coghlan, 2007; Coghlan, 2019). Role conflict can also be evident when information is provided to the researcher (Holian, 1999) as it may not always be clear from the researcher's point of view if the information has been provided to them as a researcher or in their standard role. Maintaining the boundaries between roles can be difficult.

Conducting insider research can result in disapproval due to the researcher researching their own workplace and in doing so, they may not be objective. There may be pressure to achieve a certain outcome with the research which can result in a lack of impartiality (Costley et al., 2010).

Drake (2010) asserts that by being close to the field, the insider may actually compromise their ability to critically review the information that is obtained. Because the researcher is too close to the field, there is the potential that they may make conclusions which are incorrect (Floyd \& Arthur, 2012), biased (DeLyser, 2001), they may not see aspects of the information because it has "become normalised" and not obvious (Coghlan, 2007; Costley et al., 2010; Trowler, 2011) and they may not see the 'bigger picture" (Herrmann, 1989). Furthermore, because the researcher is in the field constantly, they may not identify the importance of some issues which an outside might recognize (Saidin \& Yaacob, 2016).

Because the inside researcher has knowledge about the topic and the research field, it is possible that they will "be heavily influenced by his past experiences regarding the topic as compared to an outsider researcher who has no prior background information about the topic, making him more objective when reporting about the things the participants said during the research" (Saidin \& Yaacob, 2016). In addition, the insider researcher may think they fully comprehend the environment of study, when in actual fact their view may only be part of the picture (Ferguson \& Ferguson, 2001). There is also the potential for the researcher to misrepresent information because the researcher works within the field and will need to continue working with participants - "pragmatism may outweigh candour' (Mercer, 2007).

Moore (2012) conducted insider research within the University of East Anglia, School of Nursing Sciences and she discussed the recruitment dilemmas she experienced when an insider. In reflecting on who she recruited as participants, she had to consider if those selected were based on personal preference, true relevance to the study or if they were people who were likely to agree with her point of view. She also considered that there was the potential that she could take advantage of her friendships in the field and coerce colleagues to assist with her research. Some participants may feel pressured to participate (Costley et al., 2010; McDermid et al., 2014) due to their fear of adverse consequences at work or with the researcher if they do not take part (McDermid et al., 2014).

While having a letter of support from the organisation provides legitimacy for the work that the insider researcher is undertaking, it also has the potential to coerce participants into being involved which may result in the validity of the data collected coming under question (Sarah et al., 2002).

Interviewing participants was found challenging by several authors. Drake discusses that some information provided by Platt, where "she draws attention to, and problematises how shared knowledge of the workplace, shared knowledge of respondents domestic circumstances, and sometimes shared collegial practices under investigation make it difficult for the researcher to adopt a neutral or non-committal persona," (Drake, 2010).

Saidin and Yaacob (2016); DeLyser (2001); Herrmann (1989); Kanuha (2000) and Mitchell (2008) found that during the interview phase of data collection, interviewees assumed that the researcher already knew what they knew and was going to say so they didn't provide information at the depth required for the research. Saidin \& Yaacob found that they had to prompt the participant to provide further information. Though DeLyser suggested that probing for further information "may just aggravate the interviewee."

Mitchell (2008) when reflecting on the interviews he conducted, identified that there were times during interviews when he didn't as for as much as much detail as he should have due to the fact that he felt that he understood what was being described or alluded to. He also identified that the status or role of the researcher 
in relation to the participants may also impact on the type and amount of information that is provided, to the point that some may not even provide any information. Brannick and Coghlan (2007) and Kanuha (2000) build on this further indicating that the inside researcher may not probe as much as an outsider during interviews as they may assume too much.

Because the researcher knows the participants, it may mean that when the participants respond to questions posed by the researcher, they "may have pre-formed expectations of your alignments and preferences in ways which change their responses" (Taylor, 2011). This interview bias may result in the respondent providing information that does not accurately reflect their own response but to what they believe the researcher wants to hear. Another challenge due to researcher - participant familiarity is that the researcher maybe distracted throughout the interview due to considering the information provided by the interviewee due to the personal relationship that exists (Kanuha, 2000).

An additional challenge when interviewing is identified by Floyd and Arthur (2012) where they state that "insider researchers have to consider to what extent they should use their inside knowledge to question or discuss an interviewee's account." The use of further questioning may result in the researcher guiding the discussion to suit the outcome the researcher desires.

Due to the researcher being known to many of the participants, it can be difficult to ensure the anonymity of the participants in documentation (Costley et al., 2010; Floyd \& Arthur, 2012). Rooney (2005) identifies that the quality of the data may be impacted due to confidentiality concerns. Participants may not provide full or accurate information if they are concerned that they may be identifiable in the report or that their information may be made available to colleagues.

The challenge that received the most discussion related to the impact that conducting insider research may have on the personal relationships that the researcher has within the field. Impacts on personal relationships include:

- Confidential Information about colleagues or the employing organisation surfacing during the research which may negatively impact the relationship with the inside researcher (Greene, 2014).

- Power struggles with participants, especially with peers (Costley et al., 2010; Greene, 2014)

- Power imbalance with participants (Moore, 2012) which may place pressure on participants.

- A breakdown in the overall communication between the researcher and participants as participants can be reluctant to identify their knowledge on the topic, "perhaps for fear of being judged." (Herrmann, 1989)

- The researcher feeling obligated to reciprocate in various ways with participants (Chavez, 2008)

- The researcher has to live with the findings of their research. If the participants and the researcher continue to work for the same organisation for a time period after the research, this may cause be the cause of problems (Brannick \& Coghlan, 2007; Drake, 2010; McDermid et al., 2014).

- How to manage information of a personal nature obtained during research about colleagues and other participants which may cause problems in the workplace (Floyd \& Arthur, 2012)

- The loss of friends and constructive working relationships, or even in the extreme, losing one's job (Coghlan \& Holian, 2007; Herrmann, 1989)

- The inside researcher can have close friendships in the workplace and this may influence the researcher's work (Taylor, 2011). Knowing the participants personally will impact the way that the researcher relates to them. "Knowing when not to overstep the line between friend and researcher is a vital skill that the intimate insider must develop" (Greene, 2014)

- The "researcher is an instrument in her/his research" and "cannot conveniently tuck away the personal behind the professional, because fieldwork is personal” England cited in DeLyser (2001)

- Relations with friends and colleagues change from being "one of the gang" to being a researcher (DeLyser, 2001).

\section{Strategies to Assist with Insider Research}

It has been established that there are specific challenges to conducting insider research. However, this does not mean that insider research should be avoided. Rather, there are ten strategies which can be employed to mitigate the negative situations when conducting insider research as follows.

1. Use of multiple sources of information and different types of information gathering (Breen, 2007; Greene, 2014). This could include using a mixed methods approach where both qualitative and quantitative methods are employed (Greene, 2014).

2. Greene (2014) and Adam (2013) recommend the use of field journals and activity logs as reflexive techniques to aid the insider researcher to reflect on the research process. This will help the researcher understand themselves during the research process as well as the information gathered. "Self-critique and reflexivity can allow the insider researcher to gain some distance from the familiar and unlearn the seemingly natural ways of their own behaviour and that of their friends (Greene, 2014). 
3. Debriefing with the researcher's colleagues and supervisor. "This allows the researcher to think critically about the research, test hypotheses, and to acknowledge and feelings that may affect judgement." (Greene, 2014).

4. Aiming to maintain some distance from the participants and the subject matter. Greene (2014) used a research assistant to complete interviews of participants who were well known to her outside of the work environment. The researcher should not discuss with participants and others their opinions on the topic being researched as this may have the potential to "contaminate their data" (Mercer, 2007). "Insiders need to develop strong observational skills that help them to differentiate what they know from what they see."(Chavez, 2008).

5. When conducting interviews, Mercer (2007) consciously tried to limit her input into the conversation so as to reduce the potential of leading the informant into saying particular things. Ensure the interview area is private so that the informant's participation is not identified to ensure confidentiality. This "prevents anyone knowing about their participation, as this could potentially affect working relationships or career opportunities" (McDermid et al., 2014). Providing a detailed description of the informants and the interview setting was provided to provide transparency for the readers (Breen, 2007). Breen (2007) provided a copy of the interview transcript to the informant to allow them to review and clarify if necessary. However, Mercer (2007) did not employee this technique as they felt that "the perspectives of individual informants may be ambivalent at any given moment, may change over time, and may contradict one another to such an extent that consensus is impossible."

6. Starting interviews with a disclaimer (Chavez, 2008; DeLyser, 2001) to prompt participants who have a relationship with the researcher to provide more detailed information rather than resorting to the use of implied information. Chavez started her interviews with "I know that we have probably talked about some of the things I might ask. But I want you just to pretend as if we were talking about them for the first time, so we can make sure we get the information right." Being deliberate during interviews to ask participants to clarify or elaborate on what they were talking about (Kanuha, 2000). "This type of clarifying probe uncovered richer and more intricate analyses than those elicited through presumptive, coded communication." Kenneally (2013) found the use of semi-structured interviews enabled her to ask further questions and vary the order of questions to enable quality information to be gained.

7. Because the research journey is one that cannot be fully known in advance (Humphrey, 2007) recommended that it was important for the researcher to have a trusted social network with other insider researches and "with tried-and-tested-and-trusted others (insiders or outsiders)". Coghlan (2007) described this as having "an internal support system". Humphrey (2007) also recommends the use of relaxation and meditation techniques to "clear out' the clutter of our own body-mind". Being open and noticeable when gathering information and to avoid being secretive (Moore, 2007).

8. Being very clear throughout the organisation regarding the voluntary nature of participation in the research (Holian \& Brooks, 2004; McDermid et al., 2014). This particularly important when participants are those that may be junior to or a colleague of the researcher so that the participants do not feel under pressure to participate. "Equally important, where individuals choose not to participate in the research that decision must be fully respected and must not lead to any adverse consequences (Holian \& Brooks, 2004). McDermid et al. (2014) recommend providing information packages outlining the risks and benefits of taking part in the study" and should include "the right to withdraw as a participant at any stage of the process without explanation, consequence or repercussions." Obtaining a letter of support from senior management gives "the researcher and the research topic organizational legitimacy" (Sarah et al., 2002). If this is not obtained, then it is possible that the research work may be disregarded.

9. Taking time away from the work and research environment when completing the write up to allow objectivity and give some perspective (Kenneally, 2013). Having a life outside of the research project to give some downtime. "Stay alive - care for yourself" Shepard in Coghlan (2019).

10. Open communication with participants will help the researcher to gain valuable insights and rich data collection. A breakdown in the overall communication between the researcher and participants can lead to them being reluctant to identify their knowledge on the topic, or even a fear of judgement (Herrmann, 1989).

These strategies are then posited with the 4 advantages from Figure 2, to create a "Model of Mitigation" for Insider Research, extending the model as shown in Figure 3, to include mitigating strategies for successful insider research.

\section{Discussion on Insider Research}

An insider researcher is in a unique position to research a particular issue with special knowledge (Costley et al., 2010). While conducting insider research is a complex process, it also has with it many benefits, but as this research has shown it also poses significant opportunities (Greene, 2014). Insider research has both 
advantages and disadvantages, with many authors defining this kind of research as a double-edged sword (Mercer, 2007; Mitchell, 2008; Moore, 2007). Tietze (2012) discusses this issue as she reflected on the research project she did set on her employing organisation. She identifies that this kind of research is a "balancing act between 'strangeness' and 'familiarity”.

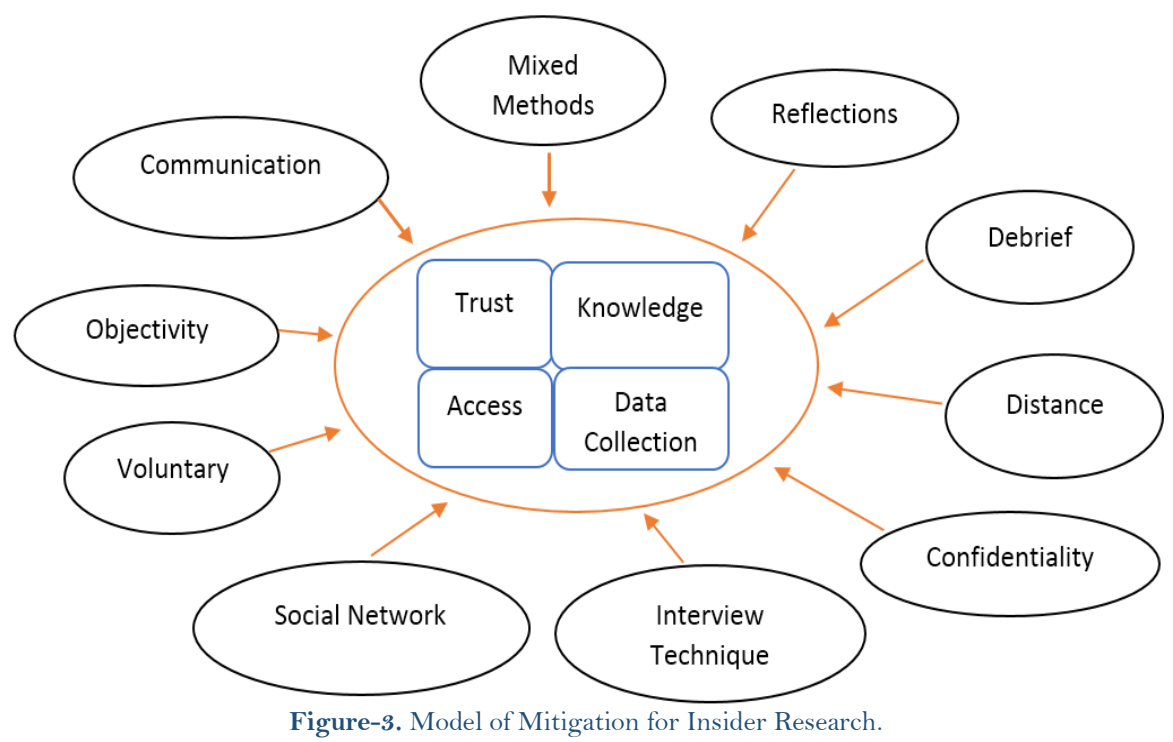

Greene (2014) believes that researchers should not worry about being either an insider or an outsider. But rather they should try to be both as there is much to be gained from both perspectives. Being an inside researcher does not make one a better or worse researcher, but just "makes me a different type of researcher" (Dwyer \& Buckle, 2009).

Overall, it doesn't matter what kind of researcher one is, but an important thing is that the research is conducted ethically and "that the objectives of their research are achieved without bias" (Saidin \& Yaacob, 2016) and that any advantage one has an insider is embraced to "gain as deep an understanding as possible of the topic" of the research (Saidin \& Yaacob, 2016). Overall, integrity is the most important researcher trait (Herrmann, 1989).

Fraser discusses their insider research journey in Rooney (2005) where she indicated that "carrying out detailed research is a time-consuming task which can be difficult to balance with full-time employment." Kenneally (2013) reflecting on her insider research journey stated that "No-one can prepare you for the difficulties of research in one's own workplace." They found that "undertaking full-time work and study is difficult and exhausting. Undertaking Insider Action Research adds another dimension as it takes an emotional and physical toll..."

Yet despite these challenges, Kenneally (2013) identified that insider research can also be rewarding. They identified that it enabled them to "become a more knowledgeable and skilled practitioner" and they gained a far deeper comprehension of the workplace. they summarized her reflections by quoting the German philosopher, Nietzsche who stated "that which does not kill us makes us stronger' (1899)" and this "also applies to those intrepid explorers undertaking Insider Action Research.”

(Coghlan \& Holian, 2007) also identify that doing insider research can but difficult but is "well worth the effort." It is "exciting, demanding and invigorating prospect that contributes considerably to researchers' own learning and contributes to the development of the systems in which we work, we live and with which we have affiliations" (Coghlan, 2019). Insider research, "real-world work-based search is relevant and important" (Holian \& Coghlan, 2013). This kind of research has the ability to improve the researchers own work practices as well as those of the organisation. Conducting insider research can lead to positive change in the organisation (Costley et al., 2010), especially where the research touches policy and practice (Trowler, 2011).

\section{Conclusion}

In conclusion, Coghlan (2019) reflects that Raelin (2008) recognizes the growing body of evidence suggesting that work based projects may prove immensely beneficial to the long term success of companies. They also acknowledge that people who engage in reflection at work and undertake insider-led research can also make a significant contribution to work practices (Nixon, 2008). Conducting insider research will not be easy. However, the opportunity to make a positive contribution and improve systems in the workplace, to increase the body of knowledge and to learn and grow as an individual drives the researcher to overcome the potential obstacles so that a difference can be made, and change instigated for improvement. Using the four advantages of trust, knowledge, access and data collection along with the ten strategies of mitigation creates 
the "Model of Mitigation" a tool insider researchers can now use to assist them in conducting research within organisations of which they are an integral part.

\section{References}

Adam, A. (2013). Managing insider issues through reflexive techniques: An insider-researcher's journey. Retrieved from; https://www.researchgate.net/publication/275336987_Managing_insider_issues_through_reflexive_techniques _An_insider-researcher's_journey.

Brannick, T., \& Coghlan, D. (2007). In defense of being "native": The case for insider academic research. Organisational Research Methods, $10(1)$, 59-74. Available at: 10.1177/1094428106289253.

Breen, L. (2007). The researcher'in the middle': Negotiating the insider/outsider dichotomy. The Australian Community Psychologist, 19(1), 163-174.

Chavez, C. (2008). Conceptualizing from the inside: Advantages, complications, and demands on insider positionality. The Qualitative Report, 13(3), 474-494.

Coghlan, D. (2007). Insider action research: Opportunities and challenges. Management Research Nerws, 30(5), 335-343. Available at: https://doi.org/10.1108/01409170710746337.

Coghlan, D., \& Holian, R. (2007). Editorial: Insider action research. Action Research, 5(1), 5-10.

Coghlan, D. (2019). Doing action research in your own organisation (5th ed. Vol. 4). London: Sage Publications Ltd.

Costley, C., Elliott, G. C., \& Gibbs, P. (2010). Doing work-based research: Approaches to enquiry for insider-researchers (Vol. 1). London: Sage.

DeLyser, D. (2001). "Do you really live here?" Thoughts on insider research. Geographical Review, 91(1-2), 441-453. Available at: https://doi.org/10.2307/3250847.

Drake, P. (2010). Grasping at methodological understanding: A cautionary tale from insider research. International Journal of Research $\Xi^{\circ}$ Method in Education, 33(1), 85-99. Available at: https://doi.org/10.1080/17437271003597592.

Dwyer, S. C., \& Buckle, J. L. (2009). The space between: On being an insider-outsider in qualitative research. International Journal of Qualitative Methods, 8(1), 54-63. Available at: https://doi.org/10.1177/160940690900800105.

Ferguson, P., \& Ferguson, B. (2001). Shooting yourself in the foot? An investigation of some issues in conducting insider research. Paper presented at the Paper Presented at the Higher Education Research and Development Society of Australasia 24th Annual Conference, Newcastle, NSW.

Floyd, A., \& Arthur, L. (2012). Researching from within: External and internal ethical engagement. International Journal of Research \& Method in Education, 35(2), 171-180. Available at: https://doi.org/10.1080/1743727x.2012.670481.

Greene, M. J. (2014). On the inside looking in: Methodological insights and challenges in conducting qualitative insider research. The Qualitative Report, 19(29), 1-13.

Griffith, A. I. (1998). Insider / outsider: Epistemological privilege and mothering work. Human Studies, 21(4), $361-376$. Available at: https://doi.org/10.1023/A:1005421211078.

Hepsø, V. (2012). Doing corporate ethnography as an insider (employee). Retrieved from: https://www.researchgate.net/publication/258084978_Doing_Corporate_Ethnography_as_an_Insider_employ ee.

Herrmann, A. W. (1989). The participant observer as "insider": researching your own classroom Paper presented at the Annual Meeting of the Conference on College Composition and Communication, Seattle. https://eric.ed.gov/?id=ED303835

Herrmann, A. W. (1989). The participant observer as "insider": Researching your own classroom. Paper presented at the Paper Presented at the Annual Meeting of the Conference on College Composition and Communication, Seattle.

Holian, R. (1999). Doing action research in my own organisation: ethical dilemmas, hopes and triumphs. Action Research International, (Paper 3). Retrieved from http://www.uq.net.au/action_research/ari/p-rholian99.html

Holian, R. (1999). Doing action research in my own organisation: Ethical dilemmas, hopes and triumphs. Action Research International, 3, 1-11.

Holian, R., \& Brooks, R. (2004). The australian national statement on ethical conduct in research: Application and implementation for 'insider' applied research in business. Action Research International, 7.

Holian, R., \& Coghlan, D. (2013). Ethical issues and role duality in insider action research: Challenges for action research degree programmes. Systemic Practice and Action Research, 26(5), 399-415. Available at: https://doi.org/10.1007/s11213-012-9256-6.

Humphrey, C. (2007). Insider-outsider: Activating the hyphen. Action Research, 5(1), 11-26. Available at: https://doi.org/10.1177/1476750307072873.

Kanuha, V. K. (2000). "Being" native versus "going native": Conducting social work research as an insider. Social Work, 45(5), 439-447. Available at: https://doi.org/10.1093/sw/45.5.439.

Kenneally, A. (2013). The lived experience of insider action research in a local government setting. Paper presented at the Paper Presented at the 3rd National Local Government Researchers' Forum, Adelaide, South Australia.

Kirpitchenko, L., \& Voloder, L. (2014). Insider research method: The significance of identities in the field: SAGE Publications, Ltd.

McDermid, F., Peters, K., Jackson, D., \& Daly, J. (2014). Conducting qualitative research in the context of pre-existing peer and collegial relationships. Nurse Researcher, 21(5), 28-33. Available at: https://doi.org/10.7748/nr.2 1.5.28.e1232.

Mercer, J. (2007). The challenges of insider research in educational institutions: Wielding a double-edged sword and resolving delicate dilemmas. Oxford Review of Education, 33(1), 1-17. Available at: https://doi.org/10.1080/03054980601094651.

Merton, R. K. (1972). Insiders and outsiders: A chapter in the sociology of knowledge. American Journal of Sociology, 78(1), 9-47. Available at: https://doi.org/10.1086/225294. 
Mitchell, H. (2008). The insider researcher. In C. J. De Souza, J. (Ed.), Understanding health and social care: An introductory reader (pp. 37-44). London, UK: SAGE Publications Ltd.

Moore, B. (2007). Original sin and insider research. Action Research, 5(1), 27-39. Available at: https://doi.org/10.1177/1476750307072874.

Moore, J. (2012). A personal insight into researcher positionality. Nurse Researcher, 19(4), 11-14. Available at: https://doi.org/10.7748/nr2012.07.19.4.11.c9218.

Nixon, I. (2008). Work-based learning impact study. Retrieved from: https://www.advance-he.ac.uk/knowledgehub/work-based-learning-impact-study Higher Education Academy.

Pitman, G. E. (2002). V. outsider/insider: The politics of shifting identities in the research process. Feminism \& Psychology, 12(2), 282-288. Available at: https://doi.org/10.1177/0959353502012002017.

Raelin, J. A. (2008). Work-based learning: Bridging knowledge and action in the workplace: John Wiley \& Sons.

Rooney, P. (2005). Researching from the inside, does it compromise validity: A discussion. Level 3, 3(1), 4.

Saidin, K., \& Yaacob, A. (2016). Insider researchers: Challenges \& opportunities. Paper Presented at the International Seminar on Generating Knowledge Through Research, Universiti Utara Malaysia.

Sarah, R., Haslett, T., Molineux, J., Olsen, J., Stephens, J., Tepe, S., \& Walker, B. (2002). Business action research in practice-a strategic conversation about conducting action research in business organizations. Systemic Practice and Action Research, 15(6), 535-546.

Taylor, J. (2011). The intimate insider: Negotiating the ethics of friendship when doing insider research. Qualitative Research, 11(1), 3-22.

Tietze, S. (2012). Researching your own organisation. In G. Symon \& C. Cassell (Eds.), Qualitative organizational research core methods and current challenges: Sage.

Trowler, P. (2011). Researching your own institution. Retrieved from: https://www.bera.ac.uk/researchersresources/publications/researching-your-own-institution-higher-education. 